Article

\title{
Agricultural Eco-Efficiency: Challenges and Progress
}

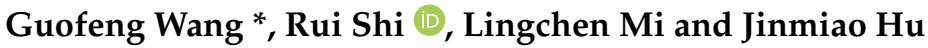

Faculty of International Trade, Shanxi University of Finance and Economics, Taiyuan 030006, China; srui3639@163.com (R.S.); mlc960214@163.com (L.M.); hujinmiao0802@163.com (J.H.)

* Correspondence: wanggf@sxufe.edu.cn

check for

updates

Citation: Wang, G.; Shi, R.; Mi, L.; $\mathrm{Hu}, \mathrm{J}$. Agricultural Eco-Efficiency:

Challenges and Progress.

Sustainability 2022, 14, 1051. https://

doi.org/10.3390/su14031051

Academic Editor: Sean Clark

Received: 15 December 2021

Accepted: 15 January 2022

Published: 18 January 2022

Publisher's Note: MDPI stays neutral with regard to jurisdictional claims in published maps and institutional affiliations.

Copyright: (c) 2022 by the authors. Licensee MDPI, Basel, Switzerland. This article is an open access article distributed under the terms and conditions of the Creative Commons Attribution (CC BY) license (https:/ / creativecommons.org/licenses/by/ $4.0 /)$.

\begin{abstract}
The research on agricultural eco-efficiency has become an important point to deeply understand the interaction between ecological and environmental conditions and socio-economic factors as well as realize the coordinated development of agricultural economic development and environmental protection. (1) Background: This paper attempts to provide scientific support for the healthy and stable development of the agricultural economy and the sustainable development of ecological agriculture. (2) Methods: From a comprehensive perspective, this paper systematically analyze the overall situation, development trend, key fields, and hot fields of agricultural ecoefficiency in the past two decades. It consists of two complementary parts, including systematic quantitative literature review (based on CiteSpace) and traditional literature review. (3) Results: Agricultural eco-efficiency has evolved significantly with the popularization of agricultural machinery and the wide application of science and technology in the field of agricultural ecology. Its future development relies on the advances in our knowledge on theories and hypothesis, evaluation methods, impact on "socio-economic ecological" system, and drivers and regulation of agricultural eco-efficiency. For each of these fields, we find that challenges still exist. At present, the quantitative methods and index selection are not unified. We should deeply analyze the internal and external driving force of the development and change of ecological efficiency by constructing a complete theoretical framework for the research of agricultural ecological efficiency. At the same time, new technologies and methods are needed to evaluate agricultural eco-efficiency, and a balanced consensus between the improvement of agricultural eco-efficiency and the improvement of the ecological environment should be formed through empirical research.
\end{abstract}

Keywords: agricultural eco-efficiency; sustainable development; literature review; progress and prospect

\section{Introduction}

Agriculture is the basic industry supporting the construction and development of the national economy. Since the reform and opening-up, China's agricultural production has grown swiftly, grain production has increased gradually, and agricultural economic output has enhanced significantly. However, agricultural development also faces profound challenges. On the one hand, agriculture's long-term sustainability faces significant challenges; over-exploitation of agricultural resources, excessive use of agricultural inputs, over-exploitation of groundwater, and the superposition of internal and external sources of pollution in agriculture are all major sources of challenge. On the other hand, agricultural ecosystem degradation is obvious; water and soil resources management, ecological compensation, and other institutional mechanisms are not sound; and water and soil resources constraints are increasingly tight, so it is very urgent to promote sustainable agricultural development [1-3]. High-intensity and rough traditional agricultural production methods have led to structural imbalance and the functional degradation of farmland ecosystems, which has attracted extensive attention [4]. How to balance food security with sustainable utilization of agricultural resources is not only an important challenge for the sustainable development of agriculture but is also the embodiment of putting the construction of ecological civilization in a prominent position in the field of agricultural eco-efficiency $[5,6]$. 
In recent years, China has achieved great advances in agricultural science and technology as well as in the economy and society. The following social, economic, and environmental challenges, however, significantly limit agricultural growth [7]. Eco-efficiency is an important index to measure the ability of sustainable development. It is introduced into the field of agriculture to form agricultural eco-efficiency (AEE). AEE is the efficiency of agricultural production, implying that the maximum agricultural economic output can be achieved with the least amount of resource consumption and pollution for a given set of material factor inputs [8]. The evaluation combines economic output, resource input, and environmental impact in the process of agricultural production. Some scholars have tried to measure the specific value of AEE in different regions, such as Italy and China. Measuring AEE is conducive to promoting the sustainable utilization of agricultural resources, realizing resource conservation and pollutant emission reduction on the basis of meeting human demand for agricultural products, and then promoting the sustainable development of regional agriculture [3,9]. The number of AEE research projects and accompanying papers has expanded considerably in recent years, but a comprehensive and systematic bibliometric analysis is lacking. In order to improve agricultural resource utilization and ensure the construction of agricultural eco-civilization, effectively sorting out the progress of agricultural eco-efficiency research, exploring the inner connection of the research results, refining their development laws, and integrating research resources and research strength is critical. In contrast, research focuses on AEE, which has been changing and adapting. As a result, the network connection between research aims and public concerns in different times must be defined. There are a few questions that must be addressed.

(1) What is the general trend of AEE research?

(2) What are the salient milestones and hot issues in AEE research?

(3) What are the major areas of AEE research?

(4) What are the challenges and future directions of AEE research?

\section{Materials and Methods}

The literature data in this paper are obtained from the Web of Science Core Collection, which could help researchers better grasp relevant topics and seek research breakthroughs and innovations by quickly discovering the research direction and development trend concerned by domestic and foreign authorities and selecting appropriate journals for submission [10]. This paper uses CiteSpace to draw various knowledge graphs. CiteSpace is a visual analysis software for scientific metrology research, and the literature data come from the Web of Science Core Collection. Compared with other renowned databases, WoS Core Collection, one of the largest and most famous citation databases, is a unique citation index where users can easily retrieve citation and trace the origin and history of a research by indexing all metadata output, including citing and cited references. In order to ensure the accuracy and reliability of literature analysis results and present the accurate research situation of AEE by foreign authors, based on several research questions, the inclusion/exclusion criteria for 268 literatures preliminarily retrieved were formulated (Table 1). The search prerequisites of AEE research were set as follows (Figure 1): "AEE = Agricultural eco-efficiency", with AEE as the theme, time span from 1900-2021, the language is English, and the literature categories are articles and review articles, excluding non-academic papers, such as meetings, proceedings, papers, and book chapters (Table 1). There are 197 records selected after excluding the literature irrelevant to the research subject. Based on Citespace.5.8.R3 (New York, USA), we set the parameters as follows: the cutting time is set as 1a (year), the threshold positioning is Top 50, and the node type is keyword [11]. Co-occurrence analysis helps us understand the distribution of object texts in the field of science domain. Relying on the keyword co-occurrence analysis of 197 records related to AEE, the literature was macroscopically visualized, and the network graph was obtained so that we could analyze AEE research frontiers and knowledge relationships. 
Table 1. Inclusion and exclusion criteria in the literature review strategies.

\begin{tabular}{ccc}
\hline & Inclusion Criteria & Exclusion Criteria \\
\hline Database selection & WoS Core Collection & Not WoS Core Collection in WoS \\
\hline Research theme & $\begin{array}{c}\text { Focusing on AEE (e.g., theories } \\
\text { and hypothesis, evaluation } \\
\text { methods, impacts, drivers } \\
\text { and regulation) }\end{array}$ & Irrelevant to AEE \\
\hline Research subjects & Foreign authors & Domestic authors \\
\hline Language & English & Non-English \\
\hline Literature categories & Articles and review articles & $\begin{array}{c}\text { Meetings, proceedings, papers, } \\
\text { book chapters }\end{array}$ \\
\hline
\end{tabular}

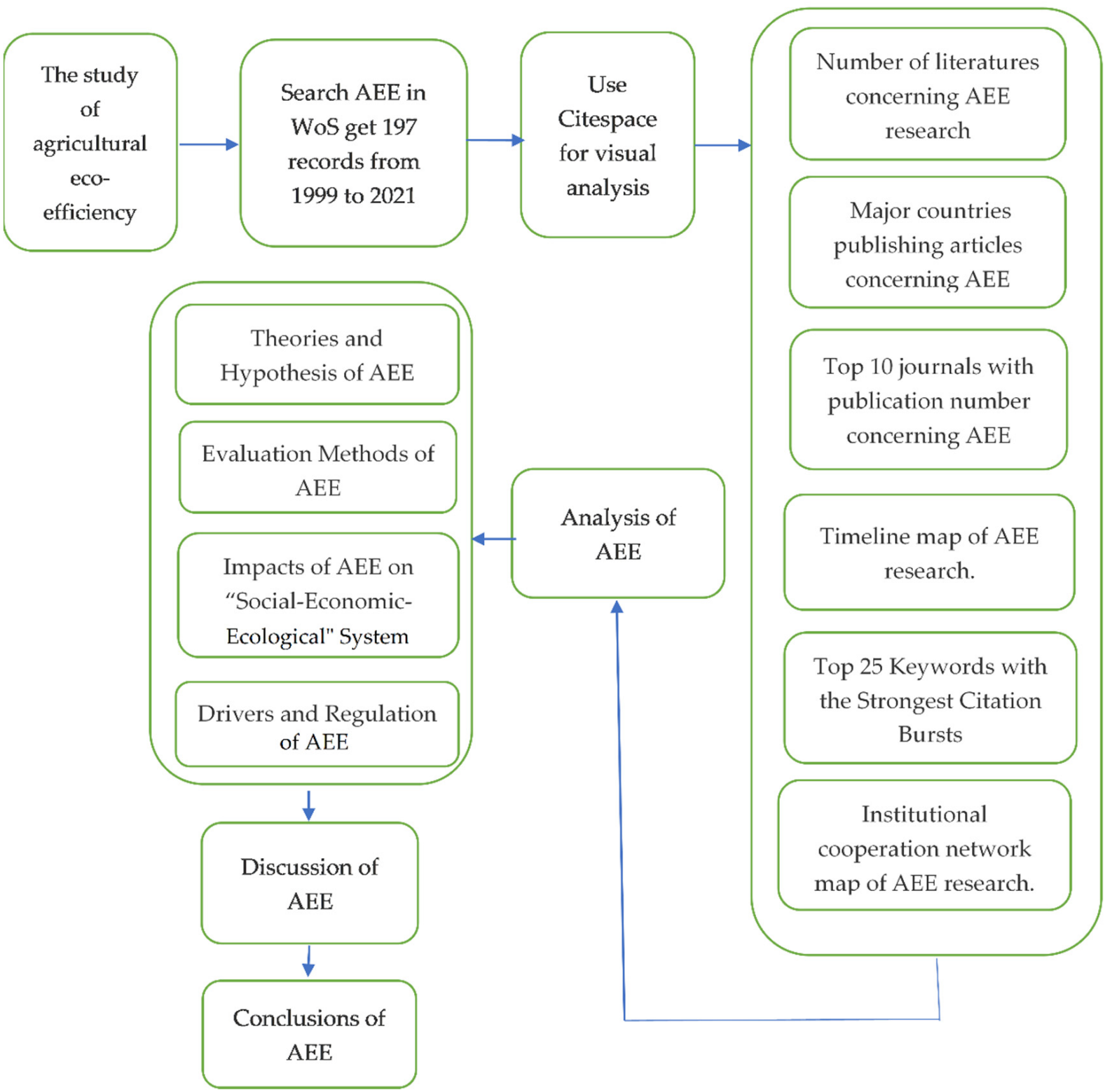

Figure 1. Method flow chart.

This review consists of two complementary parts, namely the systematic quantitative literature review (Section 3) and traditional literature review (Section 4). Systematic quantitative literature review (based on CiteSpace) establishes logical relations in the visual 
network through some factors, such as node size, network connectivity, and co-occurrence, to show the academic hotspots and research trends in this discipline field. Compared with traditional literature review, this method does not need to constantly search for relevant literature to form its own systematic understanding of the field, but it is unable to deeply review previous research. In order to make up for the shortcomings of systematic quantitative strategy, this paper further carries out the traditional literature review. Based on collecting many relevant literatures, comprehensive analysis and comments can help researchers understand the research overview and development direction in a short time, but it is often limited by the personal views of experts and the incomplete collection of data. Therefore, the combination of the two complementary strategies can make up for their respective shortcomings and, more importantly, provide strong support and demonstration for better research of AEE.

\section{Results}

\subsection{An Overview of AEE Research}

The comprehensive analysis of the number and time of documents is helpful to observe the different forms of research in a certain field in different periods. The amount and trend of published literature concerning AEE research from 1999 to 2021 were analyzed (Figure 2). We found that the amount of literatures in this field showed a fluctuating upward trend, with a rapid increase in the number of published papers after 2013. According to the number of annual publications, it can be roughly divided into two stages as follows: (1) in the initial stage (1999-2013), few annual publications were published before 2009, and a slow growth trend started in 2010. The number of papers published at this stage is relatively small, with no more than five papers published annually, indicating that the research results have failed to attract sufficient attention from the academic community, and the research results are fewer and less influential. (2) In the rapid development stage (2014-2021), the number of publications increased significantly compared with the previous period, and there was an explosive growth from 2019 to 2020. Research on AEE gradually gained attention, and scholars carried out a series of research work with various methods and perspectives from different disciplines and perspectives. To further grasp the research trends in this research field, we needed to conduct data mining of the literature in more depth to capture key information and analyze its research hotspots.

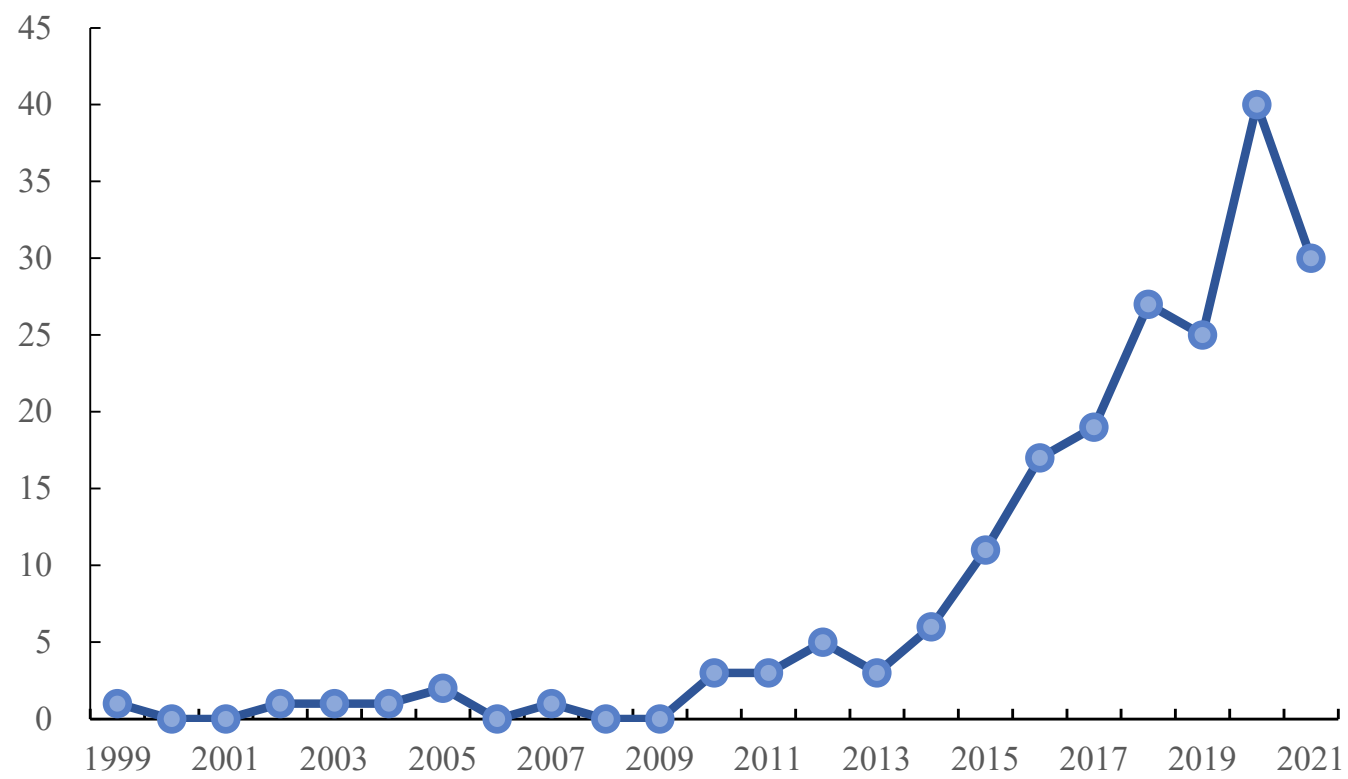

Figure 2. Quantity of literatures concerning agricultural eco-efficiency research from 1999 to 2021.

According to data from Web of Science, by the end of 2021, the top three countries in terms of the number of papers on AEE research were China (47), France (12), and 
the United States (22), followed by Germany, Greece, Italy, Australia, Sweden, Ireland, and the Netherlands (Table 2). Research on AEE has attracted extensive attention in various fields. Statistical analysis shows that AEE-related research has been published in SCI/SSCI-indexed journals covering a wide range of disciplines and fields, such as ecology, environmental science, sociology, and economics. The top 10 journals with publication volume are J Clean Prod, J Environment Manage, Ecological Economics, Agricultural Systems, Science of the Total Environment, Agriculture Ecosystems \& Environment, European Journal of Operational Research, Journal of Industrial Ecology, International Journal of Life Cycle Assessment, and European Journal of Agronomy (Figure 3).

Table 2. Major countries publishing articles concerning AEE.

\begin{tabular}{cccc}
\hline Rank & Country & Number of Articles & Centrality $\mathbf{a}^{\mathbf{a}}$ \\
\hline 1 & China & 47 & 0.45 \\
2 & France & 12 & 0.21 \\
3 & USA & 22 & 0.19 \\
4 & Germany & 13 & 0.17 \\
5 & Greece & 7 & 0.15 \\
6 & Italy & 18 & 0.12 \\
7 & Australia & 8 & 0.12 \\
8 & Sweden & 3 & 0.1 \\
9 & Ireland & 2 & 0.1 \\
10 & Netherlands & 6 & 0.09 \\
\hline
\end{tabular}

Note: a Centrality is an indicator to measure the importance of nodes in the network [12]. The larger the value of centrality is, the more the number of publications cooperated with other countries.

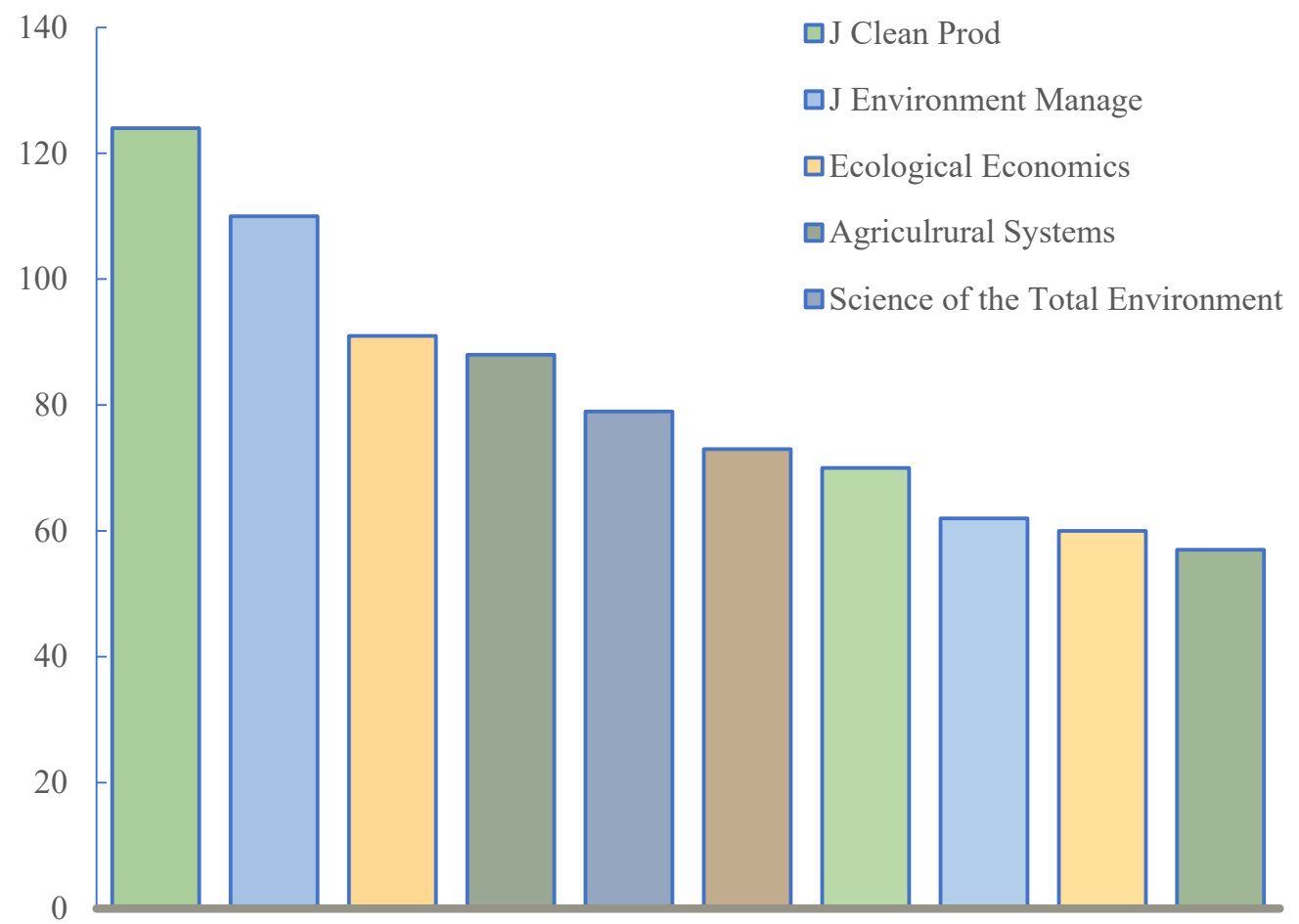

Figure 3. The top 10 journals with publication number concerning agricultural eco-efficiency during 1990-2021.

\subsection{Evolving Research Hot Topics}

\subsubsection{Analysis of Keywords and Hot Topics Distribution}

CiteSpace provides three visualization types, including cluster, timeline, and timezone views. One of them is the timeline view, which focuses on establishing the relationship between clusters as well as the temporal range of literature inside a specific cluster. CiteSpace was used to analyze the keywords and hot problems associated with AEE research 
from 1999 (there were few AEE literature earlier to this). It provides two measures for evaluating the impact of atlas rendering: modularity $Q(Q)$ and weighted mean silhouette (S). In general, the $Q$ value ranges between 0 and 1 , and $Q$ greater than 0.3 implies that the community structure has been considerably fragmented. The weighted mean silhouette is used to assess the homogeneity of the cluster. The higher the value, the more trustworthy the cluster's members will be. $\mathrm{S}>0.7$ indicates that the clustering is both efficient and compelling [13]. The result showed the modularity $Q$ and weighted mean silhouette of the cluster analysis are 0.4356 and 0.7672 , respectively, indicating that the model clustering results are scientific and reasonable. Finally, the timeline map of AEE research from 1999 to 2021 was obtained (Figure 4). Related research hot topics can be roughly divided into 10 categories, i.e., environmental impact, agriculture, industrial ecology, productivity, eco-efficiency, agricultural sector, yield gap, decoupling, farming systems, and natural fibers. There are 10 keywords with a frequency of more than 25, i.e., agriculture, ecoefficiency, life cycle assessment, environmental performance, agricultural sustainability, data envelopment analysis, greenhouse gas emission, energy use, environmental efficiency, and technical efficiency. Through the analysis of high-frequency words, it was found that the keywords of AEE research cover a wide range, and there are obvious differences in the research focus and hot topics at different stages. In general, it can be divided into the following three stages:

(1) Slow growth stage (1999-2010): This stage began to focus on agriculture, ecological efficiency, and life-cycle review. The concept of ecological efficiency was firstly put forward by Schaltegger, a famous German scholar, in the early 1990s [14]. In the following decade, academies completed multifaceted and in-depth research around the concept.

(2) Fluctuant rising stage (2010-2016): At this stage, research on environmental performance, agricultural sustainability, and greenhouse gas emissions gradually attracted attention. With the rapid development of agriculture, agricultural pollution became increasingly serious. The research focused on how to improve agricultural output and reduce agricultural production pollution to promote agricultural ecological improvement, which is an important issue for agricultural sustainable development.

(3) Rapid development stage (2016-2021): Against the background of the accelerating process of new industrialization, the improvement of agricultural productivity brought more and more serious problems of environmental pollution and resource waste, which will directly and seriously affect the long-term development of agriculture. Experts and scholars have done research on AEE from different angles and levels, including technical efficiency, land use, wastewater reuse, industrial ecology, common agricultural policy, carbon emission, and other details related to agricultural eco-efficiency.

\subsubsection{Burst Words Analysis}

The keyword emergence analysis can reflect the sudden explosive growth in the attention of a research topic in a research field within a certain period, which can show the research frontier in related research fields. Keywords are a high summary of the topics and contents of the studied literature, and their frequencies can know to a certain extent the research hotspots in the subject area in a certain time period. Burst words represent the phenomenon that the keywords to be investigated transitioned in a short period of time. It can emphasize the mutation through the investigation of word frequency. Burst terms detection in CiteSpace is used to detect emergent keywords in the AEE research from 1999 to 2021, and 25 emergent words were detected, with the highest burst intensity being soil (Table 3). It can be seen from Table 2 that there are obvious differences in research focus and hot areas at different stages. From 2010 to 2011, most of the research on AEE focused on the impact of yield, decision support, and management on ecological efficiency, which indicates that the academic community recognized the impact of energy use on agricultural eco-efficiency earlier. After 2011, academic research on AEE was gradually 
refined. From 2011 to 2016, research topics, such as agricultural production, water, soil, and crop, received more attention. From 2016 to 2021, relevant research paid more attention to the evaluation and influencing factors of AEE. Using eco-efficiency research methods, such as data envelopment analysis (DEA) and life-cycle assessment (LCA), the driving factors of AEE, sustainable and green development, and ecological intensification will become hot topics in the future.

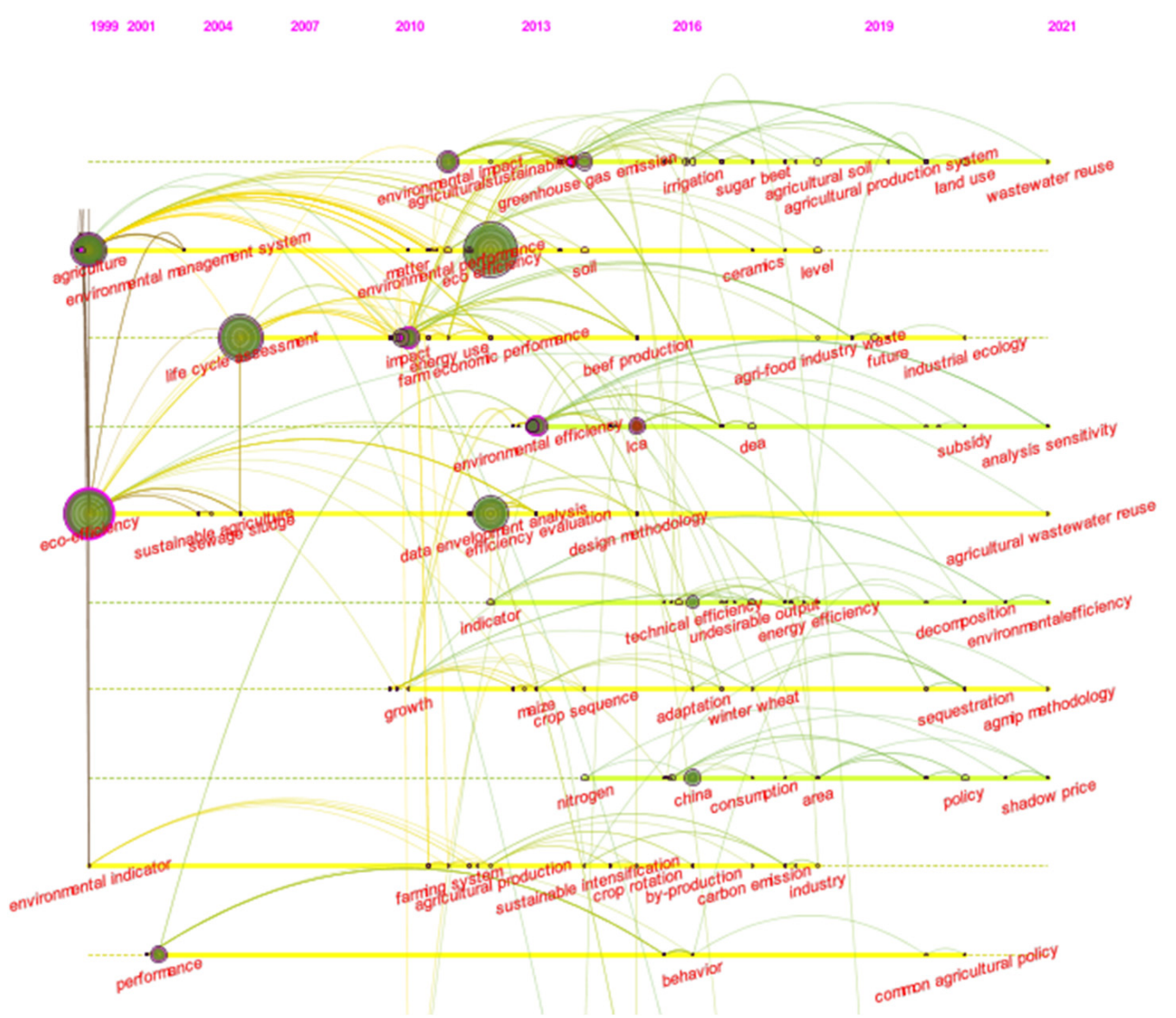

\#0 environmental impact

\#1 agriculture

\#2 industrial ecology

\#3 productivity

\#4 eco-efficiency

\#5 agricultural sector

\#6 yield gap

\#7 decoupling

\#8 farming systems

\#9 natural fibers

Figure 4. Timeline map of agricultural eco-efficiency research.

\subsubsection{Analysis of Institutional Cooperation Network}

Research collaboration network mapping is used to study the cooperation among research subjects in a disciplinary field. Citespace provides three levels of research collaboration network analysis: micro (author), middle (institution), and macro (country). The institutional cooperation network map can show how institutions are connected to each other and the contribution of each institution in the field of AEE research. Through analyzing the major research institutions and cooperation networks of AEE research, we found that AEE research received extensive attention in 57 countries and 226 research institutions around the world, yielding 226 nodes, 256 connections, and a network density of 0.0101 (Figure 5). Research institutions were dominated by universities, with the Chinese Academy of Sciences occupying the central location in the cooperation network in the field of AEE research with the largest number of articles at 14. It is followed by China Agricultural University, University of Chinese Academy of Sciences, and Poznan University of Economics and Business, all with more than five articles. In addition, Ohio State University, University of Valencia, University of Thessaly, and Agroscope Reckenholz Tanikon Res Stn ART have also published more fruitful work. By further analyzing the degree of cooperation and closeness between various institutions, we found that a clear network of collaborative research institutions centered on the Chinese Academy of Sciences has been formed. In addition, there is a lack of cooperation and communication among 
other research institutions with different research focus, and this pattern is not conducive to the sharing of research information and the development of the research system. Therefore, cooperation and communication among various related research institutions need to be strengthened in the future.

Table 3. Top 25 Keywords with the Strongest Citation Bursts during 1999-2021.

\begin{tabular}{cccccc}
\hline Keywords & Year & Strength & Begin & End & 1999-2021 b \\
\hline yield & 1999 & 1.72 & 2010 & 2013 & \\
decision support & 1999 & 1.58 & 2010 & 2014 & \\
management & 1999 & 1.02 & 2010 & 2014 & \\
energy use & 1999 & 1.69 & 2011 & 2014 & \\
firm & 1999 & 1.21 & 2011 & 2013 & \\
indicator & 1999 & 2.35 & 2012 & 2016 & \\
agricultural production & 1999 & 1.02 & 2012 & 2017 & \\
output & 1999 & 1.55 & 2013 & 2017 & \\
water & 1999 & 1.41 & 2013 & 2016 & \\
ecological intensification & 1999 & 1.24 & 2013 & 2014 & \\
maize & 1999 & 1.16 & 2013 & 2017 & \\
soil & 1999 & 2.96 & 2014 & 2015 & \\
environmental impact & 1999 & 1.32 & 2015 & 2016 & \\
crop & 1999 & 1.43 & 2016 & 2017 & \\
assessment ICA & 1999 & 1.24 & 2016 & 2017 & \\
CO ${ }_{2}$ emission & 1999 & 1.07 & 2016 & 2017 & \\
driver & 1999 & 1.05 & 2016 & 2017 & \\
DEA & 1999 & 1.84 & 2017 & 2019 & \\
cropping system & 1999 & 1.53 & 2017 & 2019 & \\
lCA & 1999 & 1.33 & 2017 & 2018 & \\
bioenergy & 1999 & 1.33 & 2018 & 2019 & \\
ecosystem service & 1999 & 2.3 & 2019 & 2021 & \\
future & 1999 & 1.53 & 2019 & 2021 & \\
intensification & 1999 & 1.21 & 2019 & 2021 & \\
food & 1999 & 1.08 & 2019 & 2021 & \\
\hline
\end{tabular}

Note: a Strength is an indicator to measure the degree of a burst event. The larger the value is, the more active the keyword is in the research field. ${ }^{\mathrm{b}}$ The red line indicates the year with active burst words, and the blue line indicates the year with inactive burst word.

\section{Poznan Univ Econ \& Business}

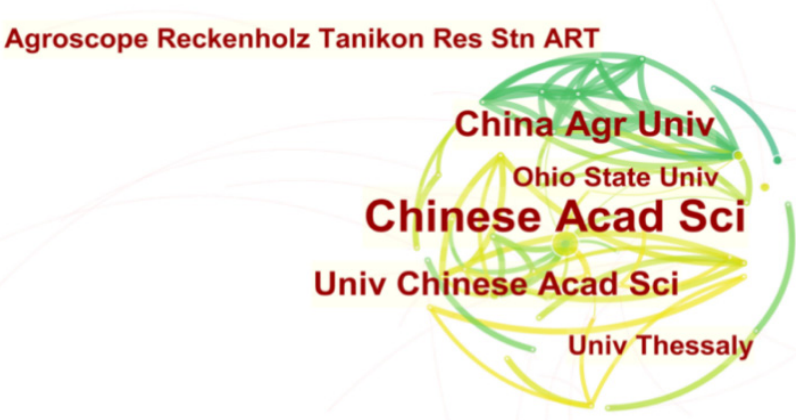

Univ Valencia

Figure 5. Institutional cooperation network map of AEE research. 


\section{Key Fields and Hot Topics of AEE Research}

\subsection{Theories and Hypothesis of AEE}

The increase in demand for agricultural products due to the population boom accelerated the transformation from traditional agriculture to petroleum agriculture. In various stages of agricultural development, agricultural production activities have a certain impact on the agricultural ecological environment at different levels. After the 1970s, with the development of "industrialized agriculture" and "petroleum agriculture", a large amount of investment in agricultural machinery, chemical fertilizers, and pesticides not only improved the efficiency of agricultural production but also caused increasing environment pollution, such as the deterioration of land fertility and serious pollution of agricultural water sources [15]. With the aggravation of the negative effects and the rising voice of sustainable development at home and abroad, promoting the development of agricultural ecology has attracted more and more attention. The basic index to measure the development level of agricultural ecology is agricultural ecological efficiency.

Human activities have modified the mode of agricultural production. As the population grows, increasing demand for food leads to the continuous improvement of agricultural output, which has brought about severe environmental problems. Western academic circles generally believe that the core affecting agricultural development lies in the improvement of production efficiency. Schultz (1975), a famous economist, proposed that the analysis of the regional distribution of agricultural modernization should start with agricultural production efficiency [16]. The above research is limited to the role of a single factor on production efficiency, while in reality, the factors influencing production efficiency are diverse. Based on it, Robert Merton Solow (1957), a Nobel economics laureate, proposed Total Factor Productivity (TFP), which plays an important role in the growth of agricultural production and its variability [17]. Schaltegger and Sturm (1992), German scholars, firstly proposed "ecological efficiency", that is, the ratio of economic growth to environmental impact, at the World Business Council for Sustainable Development (WBCSD) [14]. Subsequently, scholars in related research fields successively defined the concept of ecological efficiency from different dimensions. In 1995, Fussler introduced eco-efficiency to China [18]. After years of research, Chinese scholars have made great achievements in the field. The healthy and stable development of agriculture is the foundation of a country. Agricultural eco-efficiency is the extension and expansion of ecological efficiency in the agricultural field, that is, to obtain as much agricultural output as possible with less natural resource consumption and environmental pollution within the ecosystem in certain degree $[2,18]$. After the reform and opening-up, due to the support of "bonus system", petroleum agricultural production has made great achievements, but it has also produced negative effects, such as overuse of resources and environmental pollution, thus facing great challenges of the sustainable development of agriculture [2]. Scholars have carried out research on the conceptual connotation, theoretical models, evaluation methods, and driving mechanisms of AEE. Different scholars have different definitions of the concept of agricultural ecological efficiency, but the general direction remains the same. Some scholars believe that AEE is not only to minimize resource consumption and pollution emission but also to meet human needs for food and quality of life on the premise of ensuring sustainable development in the process of agricultural production. However, this definition ignores the environmental impact of the efficient utilization of agricultural resources on agricultural production activities [19]. Other scholars argue that agricultural production efficiency is an input-output ratio based on economic objectives, resource inputs, and environmental impacts, reflecting the sustainable development of agriculture [3]. AEE is an important indicator for evaluating the capability of agricultural sustainable development, which has certain theoretical and practical significance for formulating agricultural sustainable development policies.

Based on the special socio-economic and socio-ecology, some scholars probed the theoretical framework and hypotheses of AEE. Grossman and Kruger (1995), famous American environmental economists, put forward the improved hypothesis of "Environmental 
Kuznets Curve". The hypothesis holds that in the process of economic growth, the expansion of economic scale requires more resource investment and causes more pollution emissions [20]. In addition, the promotion and application of new technologies, the optimization and upgrading of the industrial structure, and the development and utilization of clean energy have brought positive technological progress and structural effects on environmental quality [21]. Guo, B. (2020) systematically evaluated the temporal and spatial evolution, spatial correlation characteristics, and external driving mechanism of China's AEE and analyzed the basic characteristics of agricultural production [1]. The results show that the spatial heterogeneity of agricultural production efficiency gradually appears. At the same time, the differences of natural factors, such as diversity index, NDVI, and socioeconomic factors, such as GDP ratio, affect AEE [22]. Multi-stakeholder initiatives (MSIs) have become the main institutional approach to promoting sustainability on a global scale. Konefal, J (2019) found two distinct sustainable agriculture visions. The first is to pay attention to AEE on the premise of sufficient resources, and the second is to maintain a flexible agricultural ecosystem to achieve progressive improvement in sustainability [1]. The study of AEE is of great significance to alleviate the contradiction between agricultural production and ecological environment and promote agricultural sustainable development. Therefore, how to accurately and completely define, objectively and comprehensively evaluate, and improve AEE has become an important part of agricultural economic development.

\subsection{Evaluation Methods of AEE}

Ecological efficiency is a measure index that is used to measure the impact on the ecological environment, while the production unit obtains output of economic activities [23]. There are many evaluation methods of AEE in academic circles, including the ratio analysis, life-cycle assessment (LCA), ecological footprint analysis, stochastic frontier analysis (SFA), emergy analysis, and data envelopment analysis (DEA).

\subsubsection{Ratio Analysis}

The connotation of eco-efficiency mainly includes ecological and economic efficiency [24]. Most of the early AEE evaluation methods used the ratio of economic value to resource and environmental impact. Nowadays, there is no unified and clear accounting method for evaluating AEE. The formula proposed by the World Business Council for Sustainable Development (WBSCD) is generally accepted by scholars [3], and its calculation formula is

$$
\text { Eco }- \text { efficiency }=\frac{\text { economic value of the product }}{\text { environmental impact of the product formation }}
$$

The evaluation of AEE by ratio method can be reflected in the negative impact on the environment (such as fertilizer residue and soil productivity decline) and the positive impact (such as absorption of carbon dioxide and reduction of noise) in the process of agricultural production [25]. The ratio method formula of AEE can be further expressed as

$\mathrm{AEE}=\frac{\text { economic value of agricultural products }}{\text { negative environmental effects }- \text { positive environmental effects produced by agricultural products }}$

To a certain extent, it reflects the impact of economic development on the environment, but the output side of production is considered, and the input side is ignored. However, the root cause of the environmental impact of economic development is on the input side $[26,27]$. Therefore, the method makes it difficult to distinguish different environmental impacts and cannot provide elastic support for decision makers.

\subsubsection{Life Cycle Assessment (LCA)}

Life-cycle assessment originated in the 1960s. The existence of energy problems, such as resource consumption and oil crisis, had a significant impact on social development, which led to people's exploration of energy utilization. Until the 1990s, the research on sustainable development was becoming increasingly mature. The life-cycle assessment 
method was proposed by the Society of Environmental Toxicology and Chemistry and the International Organization for Standardization [28,29]. Its formula is

$$
\frac{\text { Ecopoints }}{\mathrm{kg}}=\frac{\text { Emissions }_{A}}{\text { Emissions }_{T}} \times \frac{1}{\text { Emissions }_{T}}
$$

where Ecopoints represents ecological factors, $\mathrm{kg}$ represents waste emissions, the subscript $A$ represents the actual environmental load, and $T$ represents the ideal environmental load.

The method is mainly used to evaluate the potential environmental impact of a product in the whole life cycle and quantify it, obtaining ecological efficiency [30,31]. Due to the disadvantages of difficult boundary determination, complex data selection, and strong subjectivity, the credibility is not only often controversial, but it is difficult to make interregional comparisons.

\subsubsection{Ecological Footprint Analysis}

Ecological footprint analysis was proposed by Canadian ecologist Rees (1992) and then developed and improved by his student Wackernagel [32]. By measuring the gap between the demand of human activities for ecological services and the ecological services actually provided by nature, it evaluates whether the regional economic development is within the carrying capacity of the ecosystem. When human demand is less than the ecological carrying capacity, the natural resources of the region are in surplus in agroecosystem; conversely, it shows that the natural resources in this area are over-consumed and in deficit $[33,34]$. The method is widely used because of its simple operation, global comparability, and strong applicability. However, there are some shortcomings, such as single evaluation index, which cannot comprehensively reflect the ecological function.

\subsubsection{Stochastic Frontier Analysis (SFA)}

Stochastic frontier analysis is a parameter analysis method that is widely used in the calculation of efficiency [35]. This method was first proposed by Farrell in 1957, who calculated the cost efficiency of American agriculture and divided it into technical efficiency and allocative efficiency [36]. In 1977, Aigner, Mecusen, and Van Den Brocck independently proposed and elaborated the method [37]. The general basic form of SFA is

$$
y_{i t}=f\left(x_{i t}, t\right) \times \exp \left(v_{i t}, u_{i t}\right)
$$

where $y_{i t}$ represents the output and input elements of $i$ in period $t, t$ is time, $f($.$) represents$ the calculated production function, $v_{i t}$ is the random error term of the equation, and $u_{i t}$ is other error terms of the equation and picks the minus.

By using the method, the original production function is first determined, the actual output value and the maximum expected output value are calculated, then the two are compared, and finally the error term of the function is divided into two independent error terms: invalid rate term and random error term. This method fully takes into account the role of the random error term on the individual efficiency [38,39]. Therefore, the assessment is more accurate than the DEA. However, the method can only analyze single-output study units, and when there are complex correlations between input indicators, the evaluation results tend to have larger errors.

\subsubsection{Emergy Analysis (EMA)}

Emergy analysis, first proposed by American ecologist H.T.Odum, is a quantitative and comprehensive measurement method for a "nature-economy-society" composite ecosystem. Based on the emergy theory, the method converts different types and incomparable energy in the eco-economic system into the same standard solar energy value to balance the emergy of various energy in the system and quantitatively analyzes the structure, function, and benefit of the eco-economic system $[40,41]$. The method can be used to evaluate the 
ecological efficiency of the natural environment, carrying capacity, sustainable development, and energy utilization of the ecosystem in a certain period of time.

EMA is an approach developed at the interface between thermodynamics systems ecology. It can be used to obtain sustainability indicators and to assess the efficiency of a complex agricultural system and even all kinds of systems, such as countries and regions, while including resource, environmental, and economic values in the calculation and conducting comparative analysis in a comprehensive and integrated manner, which makes up for the deficiencies of traditional economics in which resource pricing is difficult [42,43]. However, the method also has defects, such as single evaluation index, lack of composite index, and geographical differences in energy value conversion rate.

\subsubsection{Data Envelopment Analysis (DEA)}

In 1978, A. Charnes, W.W. Cooper. and E. Rhodes proposed data envelopment analysis to evaluate the relative effectiveness of decision-making units, referred to as DEA. Since the emergence of the first DEA model CCR, a complete DEA research system of theory, method, and model has been formed. DEA model is a nonparametric analysis method based on the concept of relative probability to evaluate the relative effectiveness or benefit according to the same type of multi-input (input) and multi-output (output) decision unit (DMU) [44]. In the 1980s, the method was introduced to China and developed rapidly. In recent years, DEA has been widely used in efficiency in different fields. Anderson and Petersen (1993) put forward a three-stage super-efficiency DEA model, which allows the analysis and comparison of multiple decision units in the same production frontier [45]. Besides, the disadvantage of the traditional DEA is that it is easy to ignore the unexpected output in the calculation process and does not take into account the redundancy in the input and output variables, so it can not accurately reflect the actual efficiency [46-48]. Tone (2002) proposed the DEA-SBM, considering non-expected output and non-radial and non-angle, which effectively solved the shortcomings of DEA and truly reflected the actual efficiency [49].

\subsection{The Impacts of AEE on "Social-Economic-Ecological" System}

\subsubsection{Impacts of AEE on Social Development}

AEE is the result of the interaction between eco-environmental factors and socioeconomic factors. Influential factors of AEE include agricultural endogenous environmental problems and exogenous socio-economic factors [50,51]. On the one hand, the application of various chemical fertilizers is related to the transformation and development of agriculture, which has a significant impact on agricultural output and input [52,53]. On the other hand, socio-economic systems and policies, especially those related to sustainable agricultural development, are important external factors, which play a crucial role in influencing AEE [54].

Considering the great differences in agricultural natural resource endowment and economic development level among regions, it can be divided into two corresponding urban areas and rural areas. Urban ecological efficiency is to integrate the construction of ecological civilization into the whole process of urbanization; reflect the characteristics of ecology, personalization, and humanism; and make the coordinated development of nature, society, economy, resources, and environment [51,55]. With the construction of rural revitalization and beautiful villages, rapid urbanization has exacerbated the pressure on the ecological environment. Rural revitalization is inherent in the new urbanization. The Rural revitalization for "three rural issues" are to solve the influx of a large number of rural migrant population into cities, rural hollowing out, and poverty in the process of rapid urbanization. It also includes the harmonious coexistence between man and nature, the modernization of rural governance system, and the reconstruction of urban-rural relations [56]. In view of rural regions, AEE is not only closely related to the form of rural land use but also restricted by agricultural production and rural ecological environment [57]. The strategy to alleviate the pressure of the ecological environment in rural areas is to 
ensure that the quality of agricultural products meets people's needs on the premise of environmental and ecological sustainability and also makes ecological agriculture achieve greater development space [58]. Therefore, some scholars put forward that while ensuring the improvement of economic benefits of agricultural production, we need to pay more attention to ecological and environmental protection, make use of the development of agricultural economy to realize the coordination with environmental protection, and promote the sustainable progress of agricultural production [18,59].

\subsubsection{Impacts of AEE on Economic Growth}

The basic requirement of agricultural development is to realize the sustainable development of ecological agriculture. The agricultural production level is related to the nation's overall economic level. As the Ministry of Agriculture has increased the support of policies to support and benefit agriculture, it has provided a strong guarantee for the development of agricultural economy [60]. With the growing development of society and economy, great changes have taken place in the agricultural production mode, but compared with the rise and rapid development of other industries, the development of agricultural economy is not satisfactory [61]. Due to the rapid population growth and the increasing pressure of economic development, industrialization and urbanization have produced serious damage to the rural ecological environment, which adversely affects the stable and good development of the agricultural economy. Based on the current rural ecological environment, industrialization pollution is more serious, which has a serious impact on rural people's life [60,62]. In response to these negative effects, some scholars point out that we should strengthen the use of high and new science and technology on the basis of traditional agriculture, improve the yield of crops, promote the rapid growth of agricultural economy, and form certain social and ecological benefits [45]. At the same time, it is also necessary to pay attention to the use of ecological economic development model, reduce environmental pollution and waste of resources, optimize and improve the rural ecological environment, promote the healthy and sustainable development of agriculture, and improve the development speed of agriculture [63]. In addition, from the perspective of the industrial chain, some scholars believe that in order to realize the effective development of agricultural economy, we would constantly adjust the agricultural industrialization structure based on our own advantages, create and develop unique products, and closely connect various links and subjects, such as agricultural R\&D, production, processing, storage and transportation, marketing, brand, experience, consumption, and service [31]. With the agricultural industrialization consortium as the carrier; public platform of "industry, University, research, and application" as the carrier; and the construction of grain "production, storage, transportation, and marketing" system as the starting point, the whole agricultural industry chain could be built so as to promote the development of agricultural economy and improve the actual utilization efficiency of agricultural resources [64,65].

Production efficiency has always been the hot-spot issue researched by scholars throughout the world and plays an important role in the field of economics. As the basic element of agricultural production, land plays a role in regulating agricultural resources and realizing the coordinated development of agricultural economic development and environmental protection [2]. The internal driving force of AEE is the scarcity of agricultural water and soil resources, which are manifested in the difficulty in carrying out land-scale management and changing the traditional mode of production. The large-scale land is a different agricultural production and management mode from the current small-scale peasant mode of operation management, which is not only conducive to the implementation of agricultural modernization techniques but also conducive to the scientific and rational use of agricultural production mode [66]. Compared with the impact of land fragmentation on the control of agricultural output and input, large-scale production can reduce the input and consumption of natural resources in the process of agricultural production and contribute to the improvement of AEE [62]. The interaction mechanism between land-scale 
level and agricultural production efficiency and its impact on the agricultural economy and ecological sustainable development has attracted extensive attention.

\subsubsection{Impacts of AEE on Ecosystem Services}

Agricultural ecosystem is an ecological economic system, which is produced and evolved from a natural ecosystem. With the advancement of agricultural modernization, in order to meet the social demand for agricultural products, a large amount of material and energy have been invested in agriculture from the outside so that the agricultural ecosystem has evolved into a highly open ecosystem [10]. Due to the influence of biological, cultural, socio-economic, and environmental factors, the agricultural ecosystem is dynamic and especially vulnerable to human interference. Some scholars evaluate the value of ecosystem services through ecosystem indicators, such as domestic pollution emissions, agricultural pollution emissions, and investment in agricultural pollution control [67-69]. The development of agriculture enlightens us that in the process of agricultural production, we must always pay attention to improving the ecological environment, reducing resource consumption, increasing external income, continuously enhancing the efficiency of energy transformation and material circulation in the agricultural system, and improving the production capacity of the ecosystem itself.

Due to the development of industry, the increase of population, the lag of agricultural infrastructure construction, and the influence of extensive management mode, the sustainable development of agriculture is facing severe challenges [58]. How to balance the improvement of AEE with the improvement of the ecological environment has become a very important issue. The abuse of agricultural chemicals, such as pesticides and chemical fertilizers, destroys the stability of the agricultural ecosystem. Insufficient input of organic fertilizer and soil erosion lead to the deterioration of rational properties of farmland [19]. In view of the environment that has caused serious ecological damage, how should we maintain the agricultural ecosystem and build multi-functional ecological agriculture? While ensuring that the quality of agricultural products meets people's needs and the economic benefits of agricultural production, we need to pay more attention to ecological and environmental protection and realize the coordination between agricultural economic development and environmental protection so as to make ecological agriculture achieve greater development space. Only by realizing the protection of ecological environment can we fundamentally improve the efficiency of agricultural production [70-72]. In addition, it is necessary to repair the environment that has caused serious ecological damage in a scientific way and focus on prevention when the ecological environment has not been found to be damaged so as to maintain the sustainable development of agricultural ecosystem [53].

\subsection{Drivers and Regulation of AEE}

\subsubsection{Research on the Driving Factors of AEE}

In most cases, dynamic analysis of AEE is needed. The research on AEE driving factors is helpful to scientifically analyze the causes, influencing factors, and improvement ways of AEE loss and is of great significance to promote the rational allocation of agricultural resources and realize the efficient, coordinated, and sustainable development of agriculture $[50,73]$. In order to explore the influencing factors of AEE, scholars have used grey correlation model, panel threshold regression model, convergence test, and the Tobit model to analyze from different angles, such as agricultural development, macro environment, and policy support [74]. Various factors interact and influence each other, which have a comprehensive and complex impact on agricultural production and management activities and agricultural sustainable development. On the one hand, with the growth of population and the increase of people's demand for food, the use of agricultural chemicals has increased in the process of agricultural production [75]. On the other hand, agricultural development has still not been able to get rid of the dilemma of "petroleum agriculture" [76]. 
In terms of agricultural development, the density of agricultural machinery has become the first driving force, which is mainly reflected in the impact of the improvement of agricultural infrastructure and the application of environmentally friendly agricultural machinery on improving AEE [77]. Secondly, the scale economy effect of agricultural production has a significant positive impact on AEE and promotes the reform of agricultural production mode [78]. In addition, although the driving force of agricultural productivity and agricultural marketization is weakened, it still maintains a strong driving force. The improvement of agricultural production capacity means that farmers' income is higher, which provides a good foundation for the improvement of AEE [1]. The promotion of marketization will increase the use of agrochemical products in agricultural production for low value-added agricultural products, which are not conducive to the promotion of modern agricultural production methods [79].

In terms of macro environment, the driving effect of industrial structure, urbanization level, and urban-rural gap in AEE has weakened, while the role of scientific and technological support for the development of ecological agriculture has become increasingly prominent $[6,18]$. The popularization and application of science and technology in agricultural production not only promotes the adjustment of industrial structure and regional sustainable development but also provides technical support for the development of ecological agriculture [80]. In addition, the level of industrialization has a negative impact on AEE. With the improvement of industrialization, harmful substances, such as oil, began to be brought into agricultural production, increasing the unexpected output of agriculture, which led to the reduction of AEE to a great extent [31].

In terms of policy support, the rural land-right confirmation policy shows a strong driving force, which illustrates that the reform of land-use right and management right has not only revitalized land, a rural factor of production and liberated rural productivity, but also promoted the development of agricultural ecology [81]. However, due to the unreasonable expenditure structure of the fiscal policy of supporting and benefiting agriculture, most of the expenditure is spent on subsidies for elements, such as chemical fertilizers, pesticides, and agricultural machinery, that restrict the improvement of AEE [82].

\subsubsection{Research on Optimal Regulation of AEE}

At present, the root of many problems of AEE lies in the contradiction between agricultural economic growth and environmental protection. The reason is that in most cases, economic development and wealth growth are at the expense of ecological quality and environmental quality. How to deal with the unity of the economic benefits and environmental benefits is the key to the optimal regulation of AEE [70]. It was found that the optimization and regulation of AEE can be divided into direct regulation and indirect regulation. On the one hand, producers and operators regulate and control the relevant factors of the agricultural ecosystem, such as agricultural biology, agricultural environment, and structure and function of agricultural ecosystem [83]. On the other hand, through means and policies, such as finance, market price, industrial communications, science, technology, culture and education, administration, and justice, producers can regulate and control the agricultural ecosystem in the process of agricultural production activities [84]. The regulation of agricultural environment and the structure and function of agricultural ecosystem is an important way to optimize and control AEE. Agricultural environmental regulation is to improve the ecological environment of agricultural organisms by regulating agricultural technical facilities related to soil, climate, and air; changing adverse environmental conditions into advantages; or weakening the harm of adverse environmental factors to agricultural production activities [85] by optimizing and upgrading the structure and function of agricultural ecosystem, realizing agricultural industrialization, promoting the overall coordination of the three rural industries, and boosting the overall coordination of agricultural biology, agricultural environment, and system structure [86,87].

In view of the problems caused by AEE, relevant government departments have formulated a series of policies to realize the coordinated and sustainable development of 
economy, society and ecological environment. The government put forward various agricultural policies, such as the national green development pilot area construction policy, green high-quality and efficient action policy, rural residential environment improvement support policy, agricultural non-point source pollution control support policy in the Yangtze River economic belt and the Yellow River Basin, northeast black land protection and utilization policy, chemical fertilizer and pesticide reduction and efficiency support policy, and the pilot policy of planting and breeding combined circular agriculture $[36,88]$. In 2014 , the U.S. agriculture act mainly reformed the price support and income subsidy policy, agricultural insurance subsidy policy, and resource and environmental protection subsidy policy [84]. The EU Common Agricultural Policy promotes regional balanced development by reducing direct subsidies, decoupling subsidies, and establishing an environmental protection subsidy system [36]. Under the framework of WTO agricultural agreement, European, American, and Japanese countries adjust in a timely way and optimize agricultural subsidy policies and gradually shift the mode of agricultural subsidy to the "green box" policy more in line with WTO rules [89]. "21th Century Agenda in China" points out that "the sustainable development of agriculture and rural areas is the fundamental guarantee and priority area of China's sustainable development" [90]. In addition, the development of efficient ecological agriculture is an effective way to correctly deal with the relationship between economic development and environmental protection. It is not only different from the "petroleum agriculture" with high input, high output, and high land productivity but also different from the organic agriculture with pure nature, self-circulation, and low labor productivity [3]. Ecological efficiency emphasizes the unity of the economic benefits and environmental benefits, which can become an important entry point for quantitative sustainable development at different levels.

\section{Discussion}

The above analysis indicates that there still exist some deficiencies on AEE research, which ought to be further improved. The literature on the impact of AEE on social and economic development and ecosystem services may teach us that the definition and index selection of AEE are not standardized, and the research is insufficient. It is worth debating whether the current AEE measurement method and index selection are scientifically sound and acceptable. At the moment, popular ecological efficiency research approaches are mainly monolithic, with the DEA model accounting for a sizable portion and no theoretical grounding [91,92]. Therefore, it is necessary to understand the internal and external driving force of the development and change of ecological efficiency from the source and deeper level, build the research theoretical framework of AEE, and then verify it with empirical analysis. With the increasingly tense constraints of agricultural resources and the continuous deterioration of the agricultural ecological environment, AEE has become a great focus in academia. The research has shifted from theoretical research, such as concept definition and significance to empirical research, mainly to the actual calculation, temporal, and spatial characteristics and influencing factors of AEE. In addition, agroecology covers a wide range, and scientific and accurate evaluation of its efficiency is a huge systematic project. In a word, the research on AEE is still in its infancy, and many problems have not reached a consensus. Bringing agricultural carbon emission and carbon sink into the efficient evaluation system can provide a reference for the sustainable development of agricultural ecosystem against a background of low-carbon agriculture and green agriculture $[68,76]$.

\subsection{AEE Research from the Perspective of Low Carbon}

Low-carbon agriculture reduces carbon emissions as much as possible in the process of agricultural production and brings into full play of the function of agricultural carbon sink, that is, "increasing the carbon sink and reducing carbon emission". The ultimate goal is low energy consumption, low emission, high carbon sink. and high efficiency in the process of agricultural production. At present, AEE research is scattered to a certain 
extent, only focusing on the evaluation of ecological efficiency. Different from the industrial system, the agricultural system has dual functions of carbon emission and carbon sink. Agricultural production activities will produce a large number of greenhouse gas, but at the same time, the agricultural ecosystem also has a strong carbon sink function [93]. Compared with industrial carbon emissions, sources of agricultural carbon emissions are diverse, which can be summarized into the following three aspects: firstly, the input of agricultural means of production, carbon emissions generated in the process of agricultural energy consumption, and agricultural waste treatment; secondly, the amount of carbon sequestration in farmland ecosystem, that is, to measure the carbon sequestration function of crops; and third is the carbon emissions from breeding animals and livestock [94,95]. Because agricultural production activities have obvious external and internal characteristics, it is of great significance to integrate agricultural carbon emissions and carbon sinks into the agricultural efficiency evaluation system and investigate AEE from the perspective of low carbon. On the one hand, farmers' excessive input of chemical fertilizers and pesticides in the process of agricultural production or the use of wrong farming methods will lead to an increase in carbon emissions. If the environmental costs caused by agricultural carbon emissions are internalized, the level of agricultural output will decline significantly. On the other hand, if we do not consider carbon sequestration produced by crops, grasslands, and forests, we will underestimate agricultural efficiency. It can be seen that carbon emission and carbon sink are important aspects of negative and positive externalities of agricultural production activities. AEE research should be comprehensively and objectively evaluate the AEE from the perspective of low carbon, taking the carbon emissions generated in the process of agricultural production as unexpected output and agricultural carbon sink as ecological output [96].

\subsection{The Impact of Farmland Ownership Confirmation Reform on AEE}

By improving the stability, security, and integrity of land rights, the confirmation of agricultural land rights significantly reduces the input and use of chemical fertilizers and pesticides and helps to promote the ecological protection of cultivated land aiming at the reduction of chemical fertilizers and pesticides. Cultivated land is the material basis carrier to achieve sustainable agricultural development and maintain national food security. The foundation of cultivating land ecological protection is its property right protection. As the vivid practice of cultivated land property right protection and the basic content of agricultural land property right reform, agricultural land right confirmation has special significance for cultivated land ecological protection [81,97]. However, whether confirmation of agricultural land rights is conducive to the ecological development of agriculture remains to be tested by experience. On the one hand, the property rights of farmland owned by farmers are no longer incomplete and fuzzy, and farmers will be willing to make decisions to reduce the investment of chemical fertilizers and pesticides [97]. On the other hand, in view of agricultural profits, if farmers expect that reducing the corresponding input cannot reach the expected output level, farmers are likely to temporarily increase the input of chemical fertilizers and pesticides [72]. Since the usual time of chemical fertilizers and pesticides is earlier than the implementation time of their policies, the expected impact of this index is unknown. In general, after the reform of rural land ownership, the right boundary of rural land property rights is clearer, the land rights and functions are more complete, and the protection of rights and interests is more powerful, which is conducive to enhancing farmers' awareness of rural land protection. The way of agricultural land ownership confirmation directly affects the use of chemical fertilizers and pesticides in the process of agricultural production and is an important factor affecting AEE.

\subsection{AEE Temporal and Spatial Characteristics and Influencing Factors}

Firstly, the temporal evolution trend and spatial distribution characteristics of AEE were analyzed, and the temporal and spatial characteristics of AEE in China were discussed. It was found that from the perspective of regional differences, there is a regional imbalance 
in the growth of AEE. The high-efficiency area of AEE is still dominated by the eastern coastal provinces, but it tends to transfer to the central and western regions [7,55]. From the perspective of time evolution, the overall AEE in China shows a fluctuating upward trend, and there are some inter-provincial differences [98]. The government should strengthen policy guidance, promote the diffusion of efficient production factors in the eastern region to the central and western regions, and gradually improve the AEE of medium- and lowefficiency areas. It can be seen that AEE is related to economic development and the overall requirements of industrial structure transformation and upgrading as well as the location conditions, resource endowment, and policy implementation effectivity and economic development level of each province.

In addition, the important driving factors of the temporal and spatial evolution of AEE were discussed from the overall national overall level and regional level. From the driving factors, the confirmation of agricultural land rights, the level of financial support for agriculture, per capita agricultural GDP, agricultural production capacity, agricultural machinery density, agricultural scale level, agricultural disaster rate, and industrialization and urbanization level play a driving role in AEE. From a national perspective, the ecological development of agriculture should start with the development of agriculture itself, make use of new environmental protection technologies, and clarify the ownership of land property rights [57]. From a regional perspective, all regions make full use of their respective regional advantages to develop ecological agriculture according to local conditions. Among them, the technological progress index contributes the most to the improvement of AEE [59]. Therefore, the key to improving AEE is to promote agricultural technology progress and management innovation and promote the transformation of extensive agricultural management mode to ecological energy consumption and intensive energy-consumption path.

\section{Conclusions}

AEE is an important index to evaluate the ability of agricultural sustainable development. The problem of eco-efficiency has been widely concerned by the public. The research on AEE is a complex system engineering under the background of increasingly serious agricultural pollution. Focusing on AEE, the purposes of this article are to investigate the progress of AEE research based on literature metrology software (CiteSpace) and literature systematic review, summarize the key areas and research hotspots of AEE research, and determine the challenges and put forward the potential direction of future research. Through systematic combing, it was found that there are some problems in the study of AEE, such as inconsistent concept definition, convergence of evaluation methods, and so on. Therefore, the index system of AEE evaluation should be improved in the future evaluation. Accurate evaluation of AEE is helpful to understand the real value of agricultural ecosystem, form an agricultural production mode of saving resources and protecting ecological environment, and then fundamentally solve the problems of agricultural ecosystem degradation and environmental pollution so as to lay a foundation for the sustainable development of agriculture. Through the above comprehensive analysis, we have drawn the following conclusions:

(1) From 1999 to 2021, the annual output of papers exhibited an upward trend, which experienced two stages of "slow development period" and "rapid development period". This trend can be explained as a sign of the increasing importance of AEE in ensuring the construction of agricultural ecological civilization. However, the cooperation and communication between research institutions are insufficient, and an effective cooperation network has not been formed among research authors.

(2) Research on AEE is characterized by a clearer and more systematic analysis of resource utilization efficiency and environmental protection in agricultural development based on the comprehensive and complex influence of various factors. The key fields and hotspots of existing AEE research can be summarized into four aspects: (i) AEE theory and 
assumptions; (ii) evaluation methods of AEE; (iii) the impact of AEE on "socio-economic ecological" system; and (iv) drivers and regulation of AEE.

(3) The complexity of AEE research requires the diversity of disciplines, evaluation methods, and research scale. It covers many disciplines and fields, such as ecology, economics, and environmental science, and integrates ratio analysis, life-cycle assessment, stochastic frontier analysis (SFA), ecological footprint analysis, emergy analysis, and data envelopment analysis (DEA). The research scale discusses the temporal and spatial evolution of AEE and its important driving factors from the national and regional levels. However, research on AEE is mainly based on the macro level, and the in-depth analysis at the micro level is not sufficient. Due to the complexity of the root causes of the deterioration of the agricultural ecological environment, there will be many ways to optimize and regulate AEE. At the same time, the improvement of relevant science and technology promotes the rapid growth of agricultural economy and forms certain social and ecological benefits.

(4) There are still many unsolved fundamental problems in the research on AEE. Theoretical research of AEE lags behind the research practice. Although considerable progress has been made in AEE research and related fields, there is no unified research theoretical framework. The pursuit of theoretical improvement should also strengthen the relationship between AEE and economic development, industrial structure transformation, and upgrading and location advantages so as to take the road of sustainable development and to ensure sustainable development. Based on the analysis of this paper, the research on AEE tends to be gradually mature and enriched in the more in-depth and detailed ways in the future research.

Author Contributions: Conceptualization, G.W.; methodology, L.M.; software, R.S.; validation, J.H.; formal analysis, R.S.; writing — original draft preparation, R.S.; writing—review and editing, J.H. All authors have read and agreed to the published version of the manuscript.

Funding: This research was funded by the National Natural Science Foundation of China, grant number 72003111 and the Strategic Priority Research Program of Chinese Academy of Sciences, (Grant No. XDA23070400).

Institutional Review Board Statement: Not applicable.

Informed Consent Statement: Not applicable.

Conflicts of Interest: The authors declare no conflict of interest.

\section{References}

1. Guo, B.; He, D.; Zhao, X.; Zhang, Z.; Dong, Y. Analysis on the Spatiotemporal Patterns and Driving Mechanisms of China's Agricultural Production Efficiency from 2000 to 2015. Phys. Chem. Earth 2020, 120, 102909. [CrossRef]

2. Liu, Y.; Zou, L.; Wang, Y. Spatial-Temporal Characteristics and Influencing Factors of Agricultural Eco-Efficiency in China in Recent 40 Years. Land Use Policy 2020, 97, 104794. [CrossRef]

3. Pang, J.; Chen, X.; Zhang, Z.; Li, H. Measuring Eco-Efficiency of Agriculture in China. Sustainability 2016, 8, 398. [CrossRef]

4. Golas, M.; Sulewski, P.; Was, A.; Kloczko-Gajewska, A.; Pogodzinska, K. On the Way to Sustainable Agriculture-Eco-Efficiency of Polish Commercial Farms. Agriculture 2020, 10, 438. [CrossRef]

5. Grzelak, A.; Staniszewski, J.; Borychowski, M. Income or Assets-What Determines the Approach to the Environment among Farmers in A Region in Poland? Sustainability 2020, 12, 4917. [CrossRef]

6. Yanlin, X.; Zijun, L.; Liang, W. Temporal Spatial Differences in and Influencing Factors of Agricultural Eco-Efficiency in Shandong Province, China. Cienc. Rural 2020, 50, e20190818. [CrossRef]

7. Wang, Y.; Zhao, G. Life Cycle Assessment of Potential Pollutant-Induced Human Capital Loss Caused by Different Agricultural Production Systems in Beijing, China. J. Clean. Prod. 2019, 240, 118141. [CrossRef]

8. Deng, X.; Gibson, J. Improving Eco-Efficiency for the Sustainable Agricultural Production: A Case Study in Shandong, China. Technol. Forecast. Soc. Chang. 2019, 144, 394-400. [CrossRef]

9. Coluccia, B.; Valente, D.; Fusco, G.; De Leo, F.; Porrini, D. Assessing agricultural eco-efficiency in Italian Regions. Ecol. Indic. 2020, 116, 106483. [CrossRef]

10. Liu, W. The Data Source of This Study Is Web of Science Core Collection? Not Enough. Scientometrics 2019, 121, 1815-1824. [CrossRef]

11. Cui, Y.; Mou, J.; Liu, Y. Knowledge Mapping of Social Commerce Research: A Visual Analysis Using Cite Space. Electron. Commer. Res. 2018, 18, 837-868. [CrossRef] 
12. Ding, X.; Yang, Z. Knowledge Mapping of Platform Research: A Visual Analysis Using VOSviewer and CiteSpace. Electron. Commer. Res. 2020. [CrossRef]

13. Hu, W.; Li, C.; Ye, C.; Wang, J.; Wei, W.; Deng, Y. Research Progress on Ecological Models in the Field of Water Eutrophication: CiteSpace Analysis Based on Data from the ISI Web of Science Database. Ecol. Model. 2019, 410, 108779. [CrossRef]

14. Kicherer, A.; Schaltegger, S.; Tschochohei, H.; Pozo, B. Eco-Efficiency. Int. J. LCA 2007, 12, 537-543. [CrossRef]

15. Fang, Y. Visualizing the Structure and the Evolving of Digital Medicine: A Scientometrics Review. Scientometrics 2015, 105, 5-21. [CrossRef]

16. Lundahl, M. 'Efficient but Poor', -Schultz', Theory of Traditional Agriculture. Scand. Econ. Hist. Rev. 1987, 35, 108-129. [CrossRef]

17. $\mathrm{Hu}, \mathrm{Z}$. Green Taxation and Total Factor Productivity. Mod. Econ. 2019, 10, 698-706. [CrossRef]

18. Zeng, L.; Li, X.; Ruiz-Menjivar, J. The Effect of Crop Diversity on Agricultural Eco-Efficiency in China: A Blessing or a Curse? J. Clean. Prod. 2020, 276, 124243. [CrossRef]

19. Yang, B.; Wang, Z.; Zou, L.; Zou, L.; Zhang, H. Exploring the Eco-Efficiency of Cultivated Land Utilization and Its Influencing Factors in China's Yangtze River Economic Belt, 2001-2018. J. Environ. Manag. 2021, 294, 112939. [CrossRef] [PubMed]

20. Yin, K.; Wang, R.; Zhou, C.; Liang, J. Review of Eco-Efficiency Accounting Method and Its Applications. Acta Ecol. Sin. 2012, 32, 3595-3605. [CrossRef]

21. Xiang, H.; Wang, Y.H.; Huang, Q.Q.; Yang, Q.Y. How Much Is the Eco-Efficiency of Agricultural Production in West China? Evidence from the Village Level Data. Int. J. Environ. Res. Public Health 2020, 17, 4049. [CrossRef] [PubMed]

22. Wang, Y.; Shen, N. Agricultural Environmental Efficiency and Agricultural Environmental Kuznets Curve Based on Technological Gap: The Case of China. Pol. J. Environ. Stud. 2016, 25, 1293-1303. [CrossRef]

23. Konefal, J.; Hatanaka, M.; Constance, D.H. Multi-Stakeholder Initiatives and the Divergent Construction and Implementation of Sustainable Agriculture in the USA. Renew. Agric. Food Syst. 2019, 34, 293-303. [CrossRef]

24. Reith, C.C.; Guidry, M.J. Eco-Efficiency Analysis of an Agricultural Research Complex. J. Environ. Manag. 2003, 68, 219-229. [CrossRef]

25. Georgopoulou, A.; Angelis-Dimakis, A.; Arampatzis, G.; Assimacopoulos, D. Improving the Eco-Efficiency of an Agricultural Water Use System. Desalination Water Treat. 2016, 57, 11484-11493. [CrossRef]

26. Czyzewski, B.; Guth, M. Impact of Policy and Factor Intensity on Sustainable Value of European Agriculture: Exploring Trade-Offs of Environmental, Economic and Social Efficiency at the Regional Level. Agriculture 2021, 11, 78. [CrossRef]

27. Costa, M.P.; Schoeneboom, J.C.; Oliveira, S.A.; Vinas, R.S.; de Medeiros, G.A. A Socio-Eco-Efficiency Analysis of Integrated and Non-Integrated Crop-Livestock-Forestry Systems in the Brazilian Cerrado Based on LCA. J. Clean. Prod. 2018, 171, 1460-1471. [CrossRef]

28. Baum, R.; Bienkowski, J. Eco-Efficiency in Measuring the Sustainable Production of Agricultural Crops. Sustainability 2020, 12, 1418. [CrossRef]

29. Lijo, L.; Lorenzo-Toja, Y.; Gonzalez-Garcia, S.; Bacenetti, J.; Negri, M.; Teresa Moreira, M. Eco-Efficiency Assessment of Farm-Scaled Biogas Plants. Bioresour. Technol. 2017, 237, 146-155. [CrossRef]

30. Canaj, K.; Mehmeti, A.; Morrone, D.; Toma, P.; Todorovi, M. Life Cycle-Based Evaluation of Environmental Impacts and External Costs of Treated Wastewater Reuse for Irrigation: A Case Study in Southern Italy. J. Clean. Prod. 2021, 293, 126142. [CrossRef]

31. Saling, P. Assessing Industrial Biotechnology Products with LCA and Eco-Efficiency. In Sustainability and Life Cycle Assessment in Industrial Biotechnology; Frohling, M., Hiete, M., Eds.; Springer International Publishing: Cham, Switzerland, 2020; Volume 173, pp. 325-357. ISBN 978-3-030-47066-1.

32. Wackernagel, M.; Galli, A. An Overview on Ecological Footprint and Sustainable Development: A Chat with Mathis Wackernagel. Int. J. Ecodynamics 2007, 2, 1-9. [CrossRef]

33. Brizga, J.; Miceikiene, A.; Liobikiene, G. Environmental Aspects of the Implementation of Bioeconomy in the Baltic Sea Region: An Input-Output Approach. J. Clean. Prod. 2019, 240, 118238. [CrossRef]

34. Jia, F.; Hubbard, M.; Zhang, T.; Chen, L. Water Stewardship in Agricultural Supply Chains. J. Clean. Prod. 2019, 235, 1170-1188. [CrossRef]

35. Rudinskaya, T.; Naglova, Z. Analysis of Consumption of Nitrogen Fertilisers and Environmental Efficiency in Crop Production of EU Countries. Sustainability 2021, 13, 8720. [CrossRef]

36. Moutinho, V.; Madaleno, M.; Macedo, P.; Robaina, M.; Marques, C. Efficiency in the European Agricultural Sector: Environment and Resources. Environ. Sci. Pollut. Res. 2018, 25, 17927-17941. [CrossRef]

37. Coelli, T. Recent Development in Frontier Modelling and Efficiency Measurement. Aust. J. Agric. Resour. Econ. 2012, 39, 219-245. [CrossRef]

38. Orea, L.; Wall, A. A Parametric Approach to Estimating Eco-Efficiency. J. Agric. Econ. 2017, 68, 901-907. [CrossRef]

39. Moutinho, V.; Robaina, M.; Macedo, P. Economic-Environmental Efficiency of European Agriculture-A Generalized Maximum Entropy Approach. Agric. Econ.-Zemed. Ekon. 2018, 64, 423-435. [CrossRef]

40. Wang, Y.; Zhao, G. A Joint Use of Life Cycle Assessment and Emergy Analysis for Sustainability Evaluation of an Intensive Agro-System in China. Environ. Dev. Sustain. 2021. [CrossRef]

41. Zeng, X.; Lu, H.; Campbell, D.E.; Ren, H. Integrated Emergy and Economic Evaluation of Tea Production Chains in Anxi, China. Ecol. Eng. 2013, 60, 354-362. [CrossRef] 
42. Bastianoni, S.; Marchettini, N.; Panzieri, M.; Tiezzi, E. Sustainability Assessment of a Farm in the Chianti Area (Italy). J. Clean. Prod. 2001, 9, 365-373. [CrossRef]

43. Wang, Y.; Lin, C.; Li, J.; Duan, N.; Li, X.; Fu, Y. Emergy Analysis of Biogas Systems Based on Different Raw Materials. Sci. World J. 2013, 2013, 415812. [CrossRef]

44. Charnes, A.; Cooper, W.W.; Rhodes, E. Measuring the Efficiency of Decision Making Units—ScienceDirect. Eur. J. Oper. Res. 1978, 2, 429-444. [CrossRef]

45. Chen, X.; Liu, X.; Gong, Z.; Xie, J. Three-Stage Super-Efficiency DEA Models Based on the Cooperative Game and Its Application on the R\&D Green Innovation of the Chinese High-Tech Industry. Comput. Ind. Eng. 2021, 156, 107234. [CrossRef]

46. Angulo-Meza, L.; Gonzalez-Araya, M.; Iriarte, A.; Rebolledo-Leiva, R.; Carlos Soares de Mello, J. A Multiobjective DEA Model to Assess the Eco-Efficiency of Agricultural Practices within the CF plus DEA Method. Comput. Electron. Agric. 2019, 161, 151-161. [CrossRef]

47. Wu, H.; Du, S.; Liang, L.; Zhou, Y. A DEA-Based Approach for Fair Reduction and Reallocation of Emission Permits. Math. Comput. Model. 2013, 58, 1095-1101. [CrossRef]

48. Vlontzos, G.; Pardalos, P.M. Assess and Prognosticate Green House Gas Emissions from Agricultural Production of EU Countries, by Implementing, DEA Window Analysis and Artificial Neural Networks. Renew. Sustain. Energy Rev. 2017, 76, 155-162. [CrossRef]

49. Tone, K.; Tsutsui, M. Network DEA: A Slacks-Based Measure Approach. Eur. J. Oper. Res. 2009, 197, 243-252. [CrossRef]

50. Han, H.; Zhong, Z.; Wen, C.; Sun, H. Agricultural Environmental Total Factor Productivity in China under Technological Heterogeneity: Characteristics and Determinants. Environ. Sci. Pollut. Res. 2018, 25, 32096-32111. [CrossRef]

51. Liang, L.; Lal, R.; Ridoutt, B.G.; Zhao, G.; Du, Z.; Li, L.; Feng, D.; Wang, L.; Peng, P.; Hang, S.; et al. Multi-Indicator Assessment of a Water-Saving Agricultural Engineering Project in North Beijing, China. Agric. Water Manag. 2018, 200, 34-46. [CrossRef]

52. Li, Z.; Sarwar, S.; Jin, T. Spatiotemporal Evolution and Improvement Potential of Agricultural Eco-Efficiency in Jiangsu Province. Front. Energy Res. 2021, 9, 2021040431. [CrossRef]

53. Maia, R.; Silva, C.; Costa, E. Eco-Efficiency Assessment in the Agricultural Sector: The Monte Novo Irrigation Perimeter, Portugal J. Clean. Prod. 2016, 138, 217-228. [CrossRef]

54. Mellon-Bedi, S.; Descheemaeker, K.; Hundie-Kotu, B.; Frimpong, S.; Groot, J.C.J. Motivational Factors Influencing Farming Practices in Northern Ghana. Njas-Wagening. J. Life Sci. 2020, 92, 100326. [CrossRef]

55. Wang, L.Y.; Xiao, Y.; Rao, E.M.; Jiang, L.; Xiao, Y.; Ouyang, Z.-Y. An Assessment of the Impact of Urbanization on Soil Erosion in Inner Mongolia. Int. J. Environ. Res. Public Health 2018, 15, 550. [CrossRef] [PubMed]

56. Wang, H.; Zhuo, Y. The Necessary Way for the Development of China's Rural Areas in the New Era-Rural Revitalization Strategy. Open J. Soc. Sci. 2018, 6, 97-106. [CrossRef]

57. Zhao, L.; Jing, R.; Yu, G. Research on the Implementation Path of Rural Revitalization Strategy Based on Computer Big Data and Industrial Revitalization. J. Phys. Conf. Ser. 2020, 1648, 022165. [CrossRef]

58. Balezentis, T.; Ribasauskiene, E.; Morkunas, M.; Volkov, A.; Streimikiene, D.; Toma, P. Young Farmers' Support under the Common Agricultural Policy and Sustainability of Rural Regions: Evidence from Lithuania. Land Use Policy 2020, 94, 104542. [CrossRef]

59. Reheul, D.; Cougnon, M.; Kayser, M.; Pannecoucque, J.; Swanckaert, J.; De Cauwer, B.; van den Pol-van Dasselaar, A.; De Vliegher, A. Sustainable Intensification in the Production of Grass and Forage Crops in the Low Countries of North-West Europe. Grass Forage Sci. 2017, 72, 369-381. [CrossRef]

60. Gava, O.; Bartolini, F.; Venturi, F.; Brunori, G.; Pardossi, A. Improving Policy Evidence Base for Agricultural Sustainability and Food Security: A Content Analysis of Life Cycle Assessment Research. Sustainability 2020, 12, 1033. [CrossRef]

61. Zhou, X.; Xue, Z.; Seydehmet, J. An Empirical Study on Industrial Eco-Efficiency in Arid Resource Exploitation Region of Northwest China. Environ. Sci. Pollut. Res. 2021, 28, 53394-53411. [CrossRef]

62. Emec, S.; Bilge, P.; Seliger, G. Design of Production Systems with Hybrid Energy and Water Generation for Sustainable Value Creation. Clean Technol. Environ. Policy 2015, 17, 1807-1829. [CrossRef]

63. Medeiros, G.; Florindo, T.; Talamini, E.; Fett Neto, A.; Ruviaro, C. Optimising Tree Plantation Land Use in Brazil by Analysing Trade-Offs between Economic and Environmental Factors Using Multi-Objective Programming. Forests 2020, 11, 723. [CrossRef]

64. Mu, W.; Kanellopoulos, A.; van Middelaar, C.E.; Stilmant, D.; Bloemhof, J.M. Assessing the Impact of Uncertainty on Benchmarking the Eco-Efficiency of Dairy Farming Using Fuzzy Data Envelopment Analysis. J. Clean. Prod. 2018, 189, 709-717. [CrossRef]

65. Zhao, R.; Liu, Y.; Zhang, Z.; Guo, S.; Tseng, M.-L.; Wu, K.-J. Enhancing Eco-Efficiency of Agro-Products' Closed-Loop Supply Chain under the Belt and Road Initiatives: A System Dynamics Approach. Sustainability 2018, 10, 668. [CrossRef]

66. Borychowski, M.; Stepien, S.; Polcyn, J.; Tosovic-Stevanovic, A.; Calovic, D.; Lalic, G.; Zuza, M. Socio-Economic Determinants of Small Family Farms' Resilience in Selected Central and Eastern European Countries. Sustainability 2020, 12, 10362. [CrossRef]

67. Coderoni, S.; Esposti, R. CAP Payments and Agricultural GHG Emissions in Italy. A Farm-Level Assessment. Sci. Total Environ. 2018, 627, 427-437. [CrossRef]

68. He, G.; Cui, Z.; Ying, H.; Zheng, H.; Wang, Z.; Zhang, F. Managing the Trade-Offs among Yield Increase, Water Resources Inputs and Greenhouse Gas Emissions in Irrigated Wheat Production Systems. J. Clean. Prod. 2017, 164, 567-574. [CrossRef]

69. Fei, R.L.; You, W.H.; Wang, H.L. Can China Achieve Its CO2 Emission Reduction Targets in Agriculture Sector? Evidence from Technological Efficiency Analysis. Int. J. Environ. Sci. Technol. 2020, 17, 4249-4264. [CrossRef] 
70. Rao, I.; Peters, M.; Castro, A.; Schultze-Kraft, R.; White, D.; Fisher, M.; Miles, J.; Lascano, C.; Bluemmel, M.; Bungenstab, D.; et al. LivestockPlus-The Sustainable Intensification of Forage-Based Agricultural Systems to Improve Livelihoods and Ecosystem Services in the Tropics. Trop. Grassl.-Forrajes Trop. 2015, 3, 59-82. [CrossRef]

71. Kyrgiakos, L.S.; Vlontzos, G.; Pardalos, P.M. Ranking EU Agricultural Sectors under the Prism of Alternative Widths on Window DEA. Energies 2021, 14, 1021. [CrossRef]

72. Hamedani, S.R.; Del Zotto, L.; Bocci, E.; Colantoni, A.; Villarini, M. Eco-Efficiency Assessment of Bioelectricity Production from Iranian Vineyard Biomass Gasification. Biomass Bioenergy 2019, 127, 105271. [CrossRef]

73. Liao, J.; Yu, C.; Feng, Z.; Zhao, H.; Wu, K.; Ma, X. Spatial Differentiation Characteristics and Driving Factors of Agricultural Eco-Efficiency in Chinese Provinces from the Perspective of Ecosystem Services. J. Clean. Prod. 2021, 288, 125466. [CrossRef]

74. You, H.; Zhang, X. Ecoefficiency of Intensive Agricultural Production and Its Influencing Factors in China: An Application of DEA-Tobit Analysis. Discrete Dyn. Nat. Soc. 2016, 2016, 4786090. [CrossRef]

75. Fridrihsone, A.; Romagnoli, F.; Cabulis, U. Environmental Life Cycle Assessment of Rapeseed and Rapeseed Oil Produced in Northern Europe: A Latvian Case Study. Sustainability 2020, 12, 5699. [CrossRef]

76. Balezentis, T.; Li, T.; Streimikiene, D.; Balezentis, A. Is the Lithuanian Economy Approaching the Goals of Sustainable Energy and Climate Change Mitigation? Evidence from DEA-Based Environmental Performance Index. J. Clean. Prod. 2016, 116, 23-31. [CrossRef]

77. Paramesh, V.; Arunachalam, V.; Nikkhah, A.; Das, B.; Ghnimi, S. Optimization of Energy Consumption and Environmental Impacts of Arecanut Production through Coupled Data Envelopment Analysis and Life Cycle Assessment. J. Clean. Prod. 2018, 203, 674-684. [CrossRef]

78. Mehmeti, A.; Todorovic, M.; Scardigno, A. Assessing the Eco-Efficiency Improvements of Sinistra Ofanto Irrigation Scheme. J. Clean. Prod. 2016, 138, 208-216. [CrossRef]

79. Magarey, R.D.; Klammer, S.S.H.; Chappell, T.M.; Trexler, C.M.; Pallipparambil, G.R.; Hain, E.F. Eco-Efficiency as a Strategy for Optimizing the Sustainability of Pest Management. Pest Manag. Sci. 2019, 75, 3129-3134. [CrossRef]

80. Han, H.; Ding, T.; Nie, L.; Hao, Z. Agricultural Eco-Efficiency Loss under Technology Heterogeneity given Regional Differences in China. J. Clean. Prod. 2020, 250, 119511. [CrossRef]

81. Eder, A.; Salhofer, K.; Scheichel, E. Land Tenure, Soil Conservation, and Farm Performance: An Eco-Efficiency Analysis of Austrian Crop Farms. Ecol. Econ. 2021, 180, 106861. [CrossRef]

82. Czyzewski, B.; Matuszczak, A.; Grzelak, A.; Guth, M.; Majchrzak, A. Environmental Sustainable Value in Agriculture Revisited: How Does Common Agricultural Policy Contribute to Eco-Efficiency? Sustain. Sci. 2021, 16, 137-152. [CrossRef]

83. Bai, H.; Tao, F. Sustainable Intensification Options to Improve Yield Potential and Ecoefficiency for Rice-Wheat Rotation System in China. Field Crops Res. 2017, 211, 89-105. [CrossRef]

84. Jirapornvaree, I.; Suppadit, T.; Kumar, V. Assessing the Environmental Impacts of Agrifood Production. Clean Technol. Environ. Policy 2021. [CrossRef] [PubMed]

85. Bharath, K.N.; Basavarajappa, S. Applications of Biocomposite Materials Based on Natural Fibers from Renewable Resources: A Review. Sci. Eng. Compos. Mater. 2016, 23, 123-133. [CrossRef]

86. Heidari, M.D.; Turner, I.; Ardestani-Jaafari, A.; Pelletier, N. Operations Research for Environmental Assessment of Crop-Livestock Production Systems. Agric. Syst. 2021, 193, 103208. [CrossRef]

87. Zou, Z.; Zeng, F.; Wang, K.; Zeng, Z.; Zhao, L.; Du, H.; Zhang, F.; Zhang, H. Emergy and Economic Evaluation of Seven Typical Agroforestry Planting Patterns in the Karst Region of Southwest China. Forests 2019, 10, 138. [CrossRef]

88. Matuszczak, A.; Kryszak, L.; Czyzewski, B.; Lopatka, A. Environment and Political Economics: Left-Wing Liberalism or Conservative Leftism-Which Is Better for Eco-Efficiency? Evidence from Poland. Sci. Total Environ. 2020, 743, 140779. [CrossRef] [PubMed]

89. Prestegard, S. Multifunctional Agriculture, Policy Measures and the WTO: The Norwegian Case. Food Econ.-Acta Agric. Scand. Sect. C 2004, 1, 151-162. [CrossRef]

90. Zeng, S.X.; Meng, X.H.; Yin, H.T.; Tam, C.M.; Sun, L. Impact of Cleaner Production on Business Performance. J. Clean. Prod. 2010, 18, 975-983. [CrossRef]

91. Khoshroo, A.; Izadikhah, M.; Emrouznejad, A. Improving Energy Efficiency Considering Reduction of CO2 Emission of Turnip Production: A Novel Data Envelopment Analysis Model with Undesirable Output Approach. J. Clean. Prod. 2018, 187, 605-615. [CrossRef]

92. Heidenreich, A.; Grovermann, C.; Kadzere, I.; Egyir, I.S.; Muriuki, A.; Bandanaa, J.; Clottey, J.; Ndungu, J.; Blockeel, J.; Muller, A.; et al. Sustainable Intensification Pathways in Sub-Saharan Africa: Assessing Eco-Efficiency of Smallholder Perennial Cash Crop Production. Agric. Syst. 2022, 195, 103304. [CrossRef]

93. Chen, R.; Zhang, R.; Han, H.; Jiang, Z. Is Farmers' Agricultural Production a Carbon Sink or Source?-Variable System Boundary and Household Survey Data. J. Clean. Prod. 2020, 266, 122108. [CrossRef]

94. Zhao, X.; Zhang, X.; Li, N.; Shao, S.; Geng, Y. Decoupling Economic Growth from Carbon Dioxide Emissions in China: A Sectoral Factor Decomposition Analysis. J. Clean. Prod. 2017, 142, 3500-3516. [CrossRef]

95. Holka, M. Assessment of Carbon Footprint and Life Cycle Costs of Winter Wheat (Triticum aestivum L.) Production in Different Soil Tillage Systems. Appl. Ecol. Environ. Res. 2020, 18, 5841-5855. [CrossRef] 
96. Ji, H.; Hoti, A. Green Economy Based Perspective of Low-Carbon Agriculture Growth for Total Factor Energy Efficiency Improvement. Int. J. Syst. Assur. Eng. Manag. 2021. [CrossRef]

97. Zhou, Y.; Shi, X.; Ji, D.; Ma, X.; Chand, S. Property Rights Integrity, Tenure Security and Forestland Rental Market Participation: Evidence from Jiangxi Province, China. Nat. Resour. Forum 2019, 43, 95-110. [CrossRef]

98. Lwin, C.M.; Nogi, A.; Hashimoto, S. Eco-Efficiency Assessment of Material Use: The Case of Phosphorus Fertilizer Usage in Japan's Rice Sector. Sustainability 2017, 9, 1562. [CrossRef] 